\title{
The relationships of elementary school students' sports participation with optimism, humor styles, and school life satisfaction
}

\author{
Jae-Eun Koo ${ }^{*}$, Kwang-Uk Lee \\ Department of Exercise \& Health, College of Arts \& Physical Education, Incheon National University, Incheon, Korea
}

The purpose of this study is to elucidate the relationships of children's sports participation with optimism, humor styles, and school life satisfaction. To achieve the study purpose, this study selected 150 subjects as a sample population among the elementary school senior students, currently participating in sports activities in metropolitan areas. As research methods, questionnaire papers were used and reliability analysis, factor analysis, correlation analysis, and multiple regression analysis were conducted by utilizing SPSS 18.0 after inputting analysis data into the computer. The study results, obtained in this study are as follows: First, the participation of children in sports had a significant effect on optimism. Second, in terms of the effect of children's sports participation on humor styles, participation frequency, participation period, and participation intensity in sports had a significant effect on affiliative humor, while participation period had an effect on enhancing humor among the sub-factors of humor styles. Third, in terms of the effect of children's sports participation on school life satisfaction, participation period had a significant effect on school life satisfaction; participation frequency had an effect on peer relations and regulation-observance; and participation intensity had an effect on peer relations and school life among the sub-factors of school life satisfaction.

Keywords: Sports participation, Optimism, Humor styles, School life satisfaction

\section{INTRODUCTION}

Due to the complexity of a rapidly changing society and overheated competition in school education, students have been weakened physically and emotionally, causing serious social problems as a result of imbalance in physique and physical strength. To achieve the educational goal titled "the cultivation of prospective Koreans who will lead the future society" under this circumstance, the importance of physical education in pursuit of a whole person through physical activities is growing bigger (Choi and Kim, 2007).

In particular, the elementary school period is the critical time because physical, emotional, mental, and behavioral development is made at this time. Above all the values and emotions embedded in this period influence individuals throughout the whole life
(Park, 2013).

In this regard, the need for sports involvement is keenly asked for to recover the deteriorated physical strength due to the lack in exercise, resolve the anxiety and tension, develop potentials, and achieve self-realization (Kim and Kim, 2003). For this reason, recently extracurricular sports activities called "sports club after school" are prevalent for elementary school students. This club is usually run by private institutions or clubs as a form of extracurricular physical education programs with a view to helping the physical and emotional development of children and improving their optimism.

A wide range of optimism has been studied as part of positive psychology. Before the 1970s, the meaning of the psychological health of a person was to admit and accept the idea that it is a state of no distortion of reality. However, many recent studies have re-
${ }^{*}$ Corresponding author: Jae-Eun Koo

Department of Exercise \& Health, College of Arts \& Physical Education, Incheon

National University, 119 Academy-ro, Yeonsu-gu, Incheon 406-772, Korea

Tel: +82-32-835-8692, Fax: +82-32-835-0715, E-mail: koojaeeun@hanmail.net

Received: February 22, 2014 / Accepted: April 15, 2014
This is an Open Access article distributed under the terms of the Creative Commons Attribution Non-Commercial License (http://creativecommons.org/licenses/by-nc/3.0/) which permits unrestricted non-commercial use, distribution, and reproduction in any medium, provided the original work is properly cited. 
vealed that the psychological state of optimistic people is more stable and positive than pessimistic people, and thereby they cope with problems more effectively (Chemers et al., 2001). In addition, optimism has a significant effect on the general affairs like peer relations or critical circumstance like a disease. The findings of the case study on the peer relationships of both optimistic students and pessimistic students (Hilsman and Garber, 1995) and a study on the relationship between optimism and school adjustment demonstrated that optimism has an effect on school adjustment (Kim and Lee, 2008). These findings show that optimism has a function of strengthening the personal capability of children, reducing the environmental crisis of children and cultivating the ability of humor leading a successful life.

Humor has an effect of calming anger and relieving tension caused by conflicts in relationships, and playing an essential role of enhancing interpersonal relationships through reducing the stress, generated by personal relationships (An et al., 2007). In addition, humor performs a role of increasing social support so that humorous people tend to be good at displaying social skills, maintain friendship by attracting people, and develop the rich network of social support (Cohen and Wills, 1985).

Ways of using a sense of humor are called humor style. While a sense of humor has a temperamental and dispositional tendency, humor styles conform to the environmental aspects as behavior (Crailk. Lampert, and Nelson, 1996). In particular, humor styles have a more effect on school life satisfaction than a sense of humor, and in view of the effect of such humor, the development of humor programs and the need for humor education are emphasized (An et al., 2007). In this context, the systematic study on the relationships of optimism, humor styles, and school life satisfaction with children's sports participation is keenly required.

The previous studies about the children's sports participation (Kim and Kim, 2010; Lee, 2010; Park, 2013) have complemented the problems of physical education class in school and physical activities, but studies about the effect of duration, frequency, and intensity in sports participation on optimism, humor styles, and school life satisfaction has not been sufficiently studied yet. In this regard, this study aims to provide basic materials necessary for the development of children's sports programs by clarifying the relationships of children's sports participation with optimism, humor style and school life satisfaction for giving a wide range of opportunities to sports participants as well as the guidance orientation of physical education in school and policy development.

The study questions for achieving the study purpose are as follows: First, the optimism will be different by the degree of chil- dren's participation in sports. Second, Humor style will be different by the degree of children's participation in sports. Third, school life satisfaction will be different by the degree of children's participation in sports.

\section{MATERIALS AND METHODS}

\section{Research subjects}

To achieve the study purpose, samples were extracted targeting senior students of elementary school who participated in sports activities in metropolitan areas as of 2013. As sampling methods, metropolitan areas were classified into four cardinal directions; north, south, east, and west in Seoul and Incheon. In four areas, two private institutes were selected respectively. In each institute (2 institutes for 4 areas), 20 subjects were selected respectively, so that total subjects were 160 . Numbers used for the actual analysis were 150 with the exception of 10 which were judged to be incomplete in response to questions and inadequate in some investigation contents. The characteristics of specific subjects are shown in Table 1.

\section{Investigation tools}

In this study, questionnaire papers performed a role of tools for data collection. As to concrete questionnaire contents, background variables were 5, which include gender, school year, participation frequency, duration, and intensity. The questions were composed of 40 items; 10 items in optimism, 15 items in humor styles, 10 items in school life satisfaction.

Each measure was composed in accordance with the study purpose in consultation with a panel of expert, and each questionnaire

Table 1. The general characteristics of study subjects

\begin{tabular}{llcc}
\hline & \multicolumn{1}{c}{ Division } & Frequency & $\%$ \\
\hline Gender & Male & 78 & 52.0 \\
\multirow{5}{*}{ School year } & Female & 72 & 48.0 \\
& 4th & 42 & 28.0 \\
& 5th & 75 & 50.0 \\
Participation frequency & 6th & 33 & 22.0 \\
& 2 times & 24 & 16.0 \\
& 3 times & 36 & 24.0 \\
Participation hours & Over 4 times & 90 & 60.0 \\
& Less than 1 & 72 & 72.0 \\
& Less than 3 & 24 & 16.0 \\
Participation period & Less than 2 & 18 & 12.0 \\
& Less than 6 months & 12 & 8.0 \\
& Less than 1 yr & 18 & 12.0 \\
& Less than 2 yr & 96 & 64.0 \\
& Less than 3 yr & 24 & 16.0 \\
\hline
\end{tabular}


paper was reconstructed through the preliminary investigation for the utilization. First, in regard to the factors of optimism, the Children's Life Orientation Test (CLOT) developed by Kim and Lee (2008) were revised and complemented in this study. This test is composed of a total of 10 items with two sub-factors; 5 in positive optimism, 5 in negative optimism.

In regard to humor styles, the scale of humor style developed by Kim (2009) based on the study of Martin (2006) was revised and complemented in this study. This scale is composed of a total of 15 items as four sub-factors; 4 items in affiliative humor, 4 items in aggressive humor, 4 items in enhancing humor, and 3 items in defeating humor.

In terms of school life satisfaction, the scale of school life satisfaction used by Lee (2010) was revised and complemented in this

Table 2. Factor analysis on optimism and reliability analysis

\begin{tabular}{lcc}
\hline & \multicolumn{2}{c}{ Optimism } \\
\cline { 2 - 3 } Items & Positive & Negative \\
\hline 1. Expectation about good thing & $\mathbf{0 . 8 6 3}$ & -0.105 \\
2. Good things occurred & $\mathbf{0 . 9 1 9}$ & -0.045 \\
3. Friends increased & $\mathbf{0 . 7 3 0}$ & -0.390 \\
4. Expectation about a great person & $\mathbf{0 . 6 2 1}$ & -0.349 \\
1. Things were different from thinking & 0.144 & $\mathbf{0 . 8 3 0}$ \\
2. Bad things ensued & -0.366 & $\mathbf{0 . 7 6 7}$ \\
4. Bad things occurred & -0.468 & $\mathbf{0 . 6 3 1}$ \\
5. Dreaming was impossible & -0.461 & $\mathbf{0 . 6 9 2}$ \\
$\quad$ Eigen value & 4.213 & 1.322 \\
$\quad$ Variance rate & 52.665 & 16.519 \\
$\quad$ Accumulation $(\%)$ & 52.665 & $\mathbf{6 9 . 1 8 4}$ \\
$\quad$ Reliability & 0.825 & 0.804 \\
KMO=0.769, BTS=206.975, $P<0.001$ & & \\
\hline
\end{tabular}

study. This scale is composed of a total of 10 items as three sub-factors; 3 items in peer relations, 3 items in regulation-observance, and 4 items in school life.

The responses of all items were made by the Likert Scale with 1 point in "not at all," and 5 points in "strongly agree."

\section{Validity and reliability}

To test the validity of questionnaire papers, the panel of expert; 2 professors in the department of health management, one $\mathrm{PhD}$ degree earner of sports sociology, and one $\mathrm{PhD}$ degree earner of leisure study held a meeting and discussed the content validity and fitness of items after reviewing the questionnaire contents to revise and complement the deficient parts. To verify the validity of measurement tools, exploratory factor analysis was conducted. To minimize the number of factors, principle component analysis was conducted. As a rotation method, varimax rotation among orthogonal rotation methods was used. In regard to factors, factors over 1 in eigen value were extracted and commonality in all items was confirmed with over 0.5 . As a result of factor analysis on 10 items about optimism, 2 factors were extracted. With the exception of 2 items, which are low in factor eigen value, a total of explanatory power was $69.184 \%$, indicated in Table 2 . To verify reliability, reliability coefficient, Cronbach's Alpha, showing internal consistency was calculated. This appeared to be $0.804-0.825$, which was equivalent to the level (0.819-0.863) of previous studies.

As a result of factor analysis on 15 items in regard to humor styles, 4 factors were extracted. With the exception of 4 items which are low in factor eigen value, a total of explanatory power

Table 3. Factor analysis on humor styles and reliability analysis

\begin{tabular}{|c|c|c|c|c|}
\hline \multirow{2}{*}{ Items } & \multicolumn{4}{|c|}{ Humor styles } \\
\hline & Affiliative & Aggressive & Enhancing & Defeating \\
\hline 2. Being refreshed with humor & 0.860 & 0.299 & 0.191 & -0.059 \\
\hline 3. Offering of laughter & 0.891 & -0.063 & 0.262 & 0.067 \\
\hline 4. Funny circumstance & 0.884 & -0.009 & -0.001 & 0.034 \\
\hline 11. Caught in weakness & 0.010 & 0.970 & -0.042 & -0.079 \\
\hline 12. Teasing with a nickname & 0.021 & 0.913 & 0.117 & 0.063 \\
\hline 14. Teasing friends & 0.140 & 0.937 & -0.079 & -0.028 \\
\hline 15. Finding laughter & 0.174 & -0.093 & 0.819 & 0.146 \\
\hline 16. Not depressed & 0.311 & 0.244 & 0.761 & 0.196 \\
\hline 19. Funny idea & 0.004 & -0.059 & 0.902 & 0.095 \\
\hline 21. Being patient with teasing & 0.126 & -0.258 & 0.255 & 0.831 \\
\hline 22. Being tolerant to be an object of ridicule & -0.066 & 0.171 & 0.118 & 0.911 \\
\hline Eigen value & 3.489 & 2.886 & 1.803 & 1.094 \\
\hline Variation rate & 31.714 & 26.233 & 16.393 & 9.944 \\
\hline Accumulation (\%) & 31.714 & 57.947 & 74.340 & 84.284 \\
\hline Reliability & 0.874 & 0.940 & 0.823 & 0.746 \\
\hline $\mathrm{KMO}=0.553, \mathrm{BTS}=401.280, P<0.001$ & & & & \\
\hline
\end{tabular}


Table 4. The factor analysis on school life satisfaction and reliability analysis

\begin{tabular}{lccc}
\hline & & School life satisfaction & \\
\cline { 2 - 3 } Items & Peer relations & Regulation-observance & School life \\
\hline 1. There is a friend to talk with & $\mathbf{0 . 8 4 4}$ & -0.031 & 0.144 \\
2. Complying with my words & $\mathbf{0 . 8 7 1}$ & -0.143 & 0.053 \\
3. Joining friends & $\mathbf{0 . 9 4 9}$ & 0.112 & -0.014 \\
4. Observance of school regulations & 0.097 & $\mathbf{0 . 9 0 8}$ & 0.204 \\
5. Regarding school items as a precious thing. & -0.245 & $\mathbf{0 . 8 2 6}$ & 0.297 \\
6. Keeping order & 0.004 & $\mathbf{0 . 9 3 3}$ & 0.236 \\
7. School life satisfaction & 0.318 & 0.430 & $\mathbf{0 . 7 5 1}$ \\
8. Confidence in school & -0.020 & 0.278 & $\mathbf{0 . 9 2 5}$ \\
$\quad$ Eigen value & 3.503 & 2.561 & 0.781 \\
$\quad$ Variance rate & 43.783 & 32.007 & 9.764 \\
$\quad$ Accumulation (\%) & 43.783 & 75.789 & 85.554 \\
$\quad$ Reliability & 0.856 & 0.899 & 0.831 \\
KM0 $=0.643$, BTS $=281.233, P<0.001$ & & & \\
\hline
\end{tabular}

Table 5. The analysis results of correlation

\begin{tabular}{|c|c|c|c|c|c|c|c|c|c|c|c|}
\hline Division & 1 & 2 & 3 & 4 & 5 & 6 & 7 & 8 & 9 & 10 & 11 \\
\hline Participation frequency & 1 & & & & & & & & & & \\
\hline Participation period & 0.037 & 1 & & & & & & & & & \\
\hline Participation intensity & $0.255^{* *}$ & $0.193^{* *}$ & 1 & & & & & & & & \\
\hline Peer relations & $0.142^{* *}$ & $0.215^{* *}$ & $0.157^{* *}$ & 1 & & & & & & & \\
\hline Regulation-observance & $0.098^{*}$ & $0.128^{* *}$ & 0.005 & $0.420^{* *}$ & 1 & & & & & & \\
\hline School life & $0.111^{* *}$ & $0.306^{* *}$ & $0.179^{* *}$ & $0.382^{* *}$ & $0.574^{* *}$ & 1 & & & & & \\
\hline Affiliative humor & $0.484^{* *}$ & $0.345^{* *}$ & $0.389^{* *}$ & $0.274^{* *}$ & $0.220^{* *}$ & $0.385^{* *}$ & 1 & & & & \\
\hline Aggressive humor & 0.040 & $0.160^{* *}$ & 0.015 & $0.239 * *$ & $0.124^{* *}$ & $0.237^{* *}$ & $0.260^{* *}$ & 1 & & & \\
\hline Enhancing humor & 0.060 & -0.010 & 0.061 & $0.237^{* *}$ & $0.098^{*}$ & $0.118^{* *}$ & $0.120^{* *}$ & $0.251^{* *}$ & 1 & & \\
\hline Defeating humor & 0.066 & 0.065 & 0.008 & $0.094^{*}$ & $0.263^{* *}$ & $0.157^{* *}$ & $0.184^{* *}$ & $0.358^{* *}$ & $0.300^{* *}$ & 1 & \\
\hline Optimism & $0.176^{* *}$ & $0.294^{* *}$ & $0.179^{* *}$ & $0.431^{* *}$ & $0.293^{* * *}$ & $0.526^{* *}$ & $0.375^{* *}$ & $0.213^{* *}$ & $0.187^{* *}$ & $0.165^{* *}$ & 1 \\
\hline
\end{tabular}

${ }^{*} P<0.05$. ${ }^{* *} P<0.01$.

Table 6. The effect of sports participation on optimism

\begin{tabular}{llcc}
\hline \multirow{2}{*}{ Variables } & \multicolumn{3}{c}{ Optimism } \\
\cline { 3 - 4 } Sports & Participation frequency & \multicolumn{1}{c}{$\beta$} & $\mathrm{t}$ \\
& Participation period & 0.143 & $3.743^{* * *}$ \\
& Participation intensity & 0.272 & $7.200^{* * *}$ \\
$\mathrm{R}$ & & & $2.300^{*}$ \\
$\mathrm{R}^{2}$ & & \multicolumn{3}{c}{0.348} \\
$\mathrm{~F}$ & \multicolumn{3}{c}{0.121} \\
\hline
\end{tabular}

${ }^{*} P<0.05 .{ }^{* * *} P<0.001$.

was 84.284 , indicated in Table 3 . To verify reliability, reliability coefficient, Cronbach's Alpha, showing internal consistency was calculated. This was shown to be 0.746-0.940, which was equivalent to the level (0.719-0.943) of previous studies. It was judged to be reasonable.

As a result of factor analysis on 10 items in regard to school life satisfaction, 3 factors were extracted. A total of explanatory power was $85.554 \%$, indicated in Table 4 . To verify reliability, reliability coefficient, Cronbach's Alpha, showing internal consistency was calculated. This was shown to be 0.831-0.899, which was equivalent to the level (0.853-0.892) of previous studies. It was judged to be a reliable scale.

\section{Research procedures and data analysis}

The analysis methods about 150 collected copies of the questionnaire paper by the SPSS 18.0 program suitable for the study purpose are as follows: First, exploratory factor analysis and reliability analysis were conducted to verify the constructive validity of questionnaire papers. Second, correlation analysis was performed to examine the correlation of variables. Lastly, multiple regression analysis was utilized to analyze the relationships of children's participation in sports with optimism, humor styles, and school life satisfaction. 
Table 7. The effect of sports participation on humor styles

\begin{tabular}{|c|c|c|c|c|c|c|c|c|c|}
\hline \multirow{3}{*}{ Variables } & & \multicolumn{8}{|c|}{ Humor styles } \\
\hline & & \multicolumn{2}{|c|}{ Affiliative humor } & \multicolumn{2}{|c|}{ Aggressive humor } & \multicolumn{2}{|c|}{ Enhancing humor } & \multicolumn{2}{|c|}{ Defeating humor } \\
\hline & & $\beta$ & $t$ & $\beta$ & $\mathrm{t}$ & $\beta$ & $\mathrm{t}$ & $\beta$ & $t$ \\
\hline \multirow[t]{3}{*}{ Sports } & Participation frequency & 0.415 & $12.997^{* * *}$ & 0.047 & 1.157 & 0.041 & 1.020 & 0.069 & 1.701 \\
\hline & Participation period & 0.285 & $9.061^{* * *}$ & -0.023 & -.561 & 0.164 & $4.129^{* * *}$ & 0.067 & 1.670 \\
\hline & Participation intensity & 0.228 & $6.991^{* * *}$ & 0.053 & 1.289 & -0.027 & -.649 & -0.023 & -.545 \\
\hline $\mathrm{R}$ & & \multicolumn{2}{|c|}{0.623} & \multicolumn{2}{|c|}{0.080} & \multicolumn{2}{|c|}{0.166} & \multicolumn{2}{|c|}{0.093} \\
\hline $\mathrm{R}^{2}$ & & \multicolumn{2}{|c|}{0.388} & \multicolumn{2}{|c|}{0.006} & \multicolumn{2}{|c|}{0.028} & \multicolumn{2}{|c|}{0.009} \\
\hline $\mathrm{F}$ & & \multicolumn{2}{|c|}{$135.377^{* * *}$} & \multicolumn{2}{|c|}{1.360} & \multicolumn{2}{|c|}{6.047} & \multicolumn{2}{|c|}{1.884} \\
\hline
\end{tabular}

${ }^{* * *} P<0.001$.

Table 8. The effect of sports participation on school life satisfaction

\begin{tabular}{|c|c|c|c|c|c|c|c|}
\hline \multirow{3}{*}{ Variables } & & \multicolumn{6}{|c|}{ School life satisfaction } \\
\hline & & \multicolumn{2}{|c|}{ Peer relation } & \multicolumn{2}{|c|}{ Regulation-observance } & \multicolumn{2}{|c|}{ School life } \\
\hline & & $\beta$ & $\mathrm{t}$ & $\beta$ & $\mathrm{t}$ & $\beta$ & $\mathrm{t}$ \\
\hline \multirow[t]{3}{*}{ Sports } & Participation frequency & 0.112 & $2.838^{* *}$ & 0.106 & $2.623^{* *}$ & 0.073 & 1.905 \\
\hline & Participation period & 0.193 & $4.988^{* * *}$ & 0.133 & $3.359^{* * *}$ & 0.283 & $7.469^{* * *}$ \\
\hline & Participation intensity & 0.074 & $2.284^{*}$ & -0.048 & -1.173 & 0.106 & $2.702^{* *}$ \\
\hline $\mathrm{R}$ & & \multicolumn{2}{|c|}{0.268} & \multicolumn{2}{|c|}{0.165} & \multicolumn{2}{|c|}{0.337} \\
\hline $\mathrm{R}^{2}$ & & \multicolumn{2}{|c|}{0.072} & \multicolumn{2}{|c|}{0.027} & \multicolumn{2}{|c|}{0.114} \\
\hline $\mathrm{F}$ & & \multicolumn{2}{|c|}{$16.556^{* * *}$} & \multicolumn{2}{|c|}{$5.984^{* * *}$} & \multicolumn{2}{|c|}{$27.416^{* * *}$} \\
\hline
\end{tabular}

${ }^{* *} P<0.01 .{ }^{* *} P<0.001$.

\section{RESULTS}

\section{Correlation analysis}

To identify multicollinearity which appears in variables, correlation of all variables was conducted and the results were shown in Table 5. The analysis results showed that the correlation coefficient of all factors was below 0.574 , which appears to be lower than 0.80 , criterion of multicollinearity. Therefore, all factors were confirmed to be different composing concepts.

\section{The effect of the elementary school students' participation in sports on optimism}

The results of the effect of elementary school students' participation in sports on optimism are illustrated in Table 6 . Three factors in sports participation; participation frequency $(\beta=0.143)$, participation period $(\beta=0.272)$, and participation intensity $(\beta=0.090)$ had a positive effect on optimism, which are significant. The independent variables used for the regression analysis gave an explanation of $12.1 \%$ of the total variance in optimism.

\section{The effect of elementary school students' sports participation on humor styles}

The results of the effect of elementary school students' participa- tion in sports are shown in Table 7. Investigating the results, participation frequency $(\beta=0.415)$, participation period $(\beta=0.285)$, and participation intensity $(\beta=0.228$ ) among the sub-factors of sports participation had an effect on affiliative humor, while participation period ( $\beta=0.164$ ) had an effect on enhancing humor. As independent variables used for the regression analysis, affiliative humor among the sub-factors of humor styles explained 38.8\% of the total variance. Aggressive humor, enhancing humor, and defeating humor give explanation of $0.6 \%, 2.8 \%$, and $0.9 \%$ of the total variance.

\section{The effect of elementary school students' participation in sports on school life satisfaction}

The results about the effect of elementary school students' participation in school life satisfaction are seen in Table 8 . The study results showed that participation frequency $(\beta=0.112)$, participation period $(\beta=0.193)$, and participation intensity $(\beta=0.074)$ had a significant effect on peer relations; participation frequency ( $\beta=0.106)$ and participation period $(\beta=0.133)$ had an effect on regulation-observance and participation period $(\beta=0.283)$; and participation intensity $(\beta=0.106)$ had an effect on school life. As to independent variables for the regression analysis, peer relations, regulation-observance, and school life among the sub-factors of 
school life satisfaction give explanation of $7.2 \%, 2.7 \%$, and $11.4 \%$ of the total variance respectively.

\section{DISCUSSION}

This study puts its major purpose in elucidating the relationships of children's sports participation with optimism, humor styles, and school life satisfaction empirically. It attempts to discuss this issue based on the study results.

First, children's participation in sports had a significant effect on optimism. This shows that long participation of children in sports activities and frequent participation would contribute to the improvement of children's confidence in sports by improving the exercise function and bond with friends. However, other findings to prove the results of this study are not sufficient yet. Nonetheless, the findings in this study are mostly consistent with other study results, revealing that children's sports participation plays a positive role in highly evaluating physical self-concept, which is the upper concept. In addition, the findings in this study correspond with the study results (Kim, 2009) that long participation and frequent participation in leisure sports activities would increase optimism to some degree. In other words, regular participation in sports can help students control environmental crisis and increase optimism, leading a successful life by strengthening the internal capability of children. Therefore, making children have a habit of regular participation in sports is considered important in developing optimism positively.

Second, in regard to the effect of children's participation in sports on humor styles, it was demonstrated that sports participation frequency, participation period, and participation intensity would have a significant effect on affiliative humor among the sub-factors of humor styles, while participation period would have a significant effect on enhancing humor. This shows that long participation of children in sports activities helps children have intimate friends and have affiliative humor and enhancing humor from humorous perspectives under any stressful event or circumstance for enhancing social relationships.

The findings of this study are considerably matched to those of Im (2009) demonstrating that long participation or frequent participation in Taekwondo would have a positive effect on pro-social behaviors. This shows that sports participation contributes to improving humor styles in both speaker and hearer. Therefore, it is judged that helping students have a habit of regular participation in sports is important in developing affiliative humor and enhancing humor style.
Third, in terms of the effect of children's sports participation on school life satisfaction, participation period had a significant effect on school life satisfaction; participation frequency had an effect on peer relations among the sub-factors of school life satisfaction; and participation intensity had a significant effect on peer relations and school life. These results show that the long participation of children in sports activity promotes low-abiding spirit which keeps round peer relations and regulations due to the development of social skills and improvement in school life satisfaction.

Likewise, the findings about the effect of the participation of children in physical activities on the inclination of personal relationships are partially consistent with the report that the participation period in sports activities has a positive effect on personal relationships (Lee, 2000) which demonstrate that physical activities have a positive effect on self-respect, self-efficacy, and school life satisfaction in her study on children's sports participation after school. In addition, it is indicative that the findings about the positive effect of children's participation in sports on regulation-observance, good-manners, and pro-social behaviors are in compliance with the importance of children's participation in sports activities. Therefore, it is judged that helping children have a habit of participating in regular sports activities is very essential for improving school life satisfaction.

\section{CONFLICT OF INTEREST}

No potential conflict of interest relevant to this article was reported.

\section{ACKNOWLEDGMENTS}

This research was conducted by the financial support of Incheon National University in 2013.

\section{REFERENCES}

An JY, Choi MS, Choi TS. The relationships of the youth' humor sense with humor style and personal relationship skills. J Korean Asso Play Thera 2007;10(4):97-108.

Choi WY, Kim MJ. A study on the elementary school students' participation in private weekend physical education institution and the recognition about school physical education class. Korea Sports Res 2007: 18(4):757-766.

Chemers MM, Hu L, Garcia BF. Academic self-efficacy and first-year college student performance and adjustment. J Educ Psychol 2001: 
93(1):55-64.

Cohen S, Wills TA. Stress, social support, and the buffering hypothesis Psychol Bull 1985:98(1):310-357.

Hilsman R, Garbrt JA. Test of the cognitive diathesis-stress model of depression in children: Academic stressors, attributional style, perceived competence and control. J Person Social Psychol 1995:69:370-380.

Kim KS, Kim, KJ. The Effect of Specialty, Aptitude Educational Activity on the Physical Fitness and Mental Health of Boys' Middle School Students. J KAHPERD 2008;42(1):573-582.

Kim SI. The vitality of leisure sports participants and the analysis on the optimism about the future and structure model of hope. J Leisure Recreation Stud 2009;33(3):181-191.

Kim JY, Lee JY. The scale development of the children's dispositional op- timism and the study of verification. Asia Edu Study 2008;8(3):83-106.

Lee SI. The Participation Motivation of After School Physical Education Programs with Sports Immersion and School Life Satisfaction. Korean Soci Study Physic Edu 2010;15(1):41-54.

Lee HG. The effect of the children's participation in sports activities on achievement motivation and the relationship tendency. Korean Soci Sociol Sport 2000;13(2):481-492.

Martin RA. The psychology of humor: An integrative approach. Trans Shin, Hyeon Jeong; Seoul: Park Hak Sa, 2006.

Park MK. The relationships of the elementary school students' motivation to participate in weekend physical education with exercise immersion, self-efficacy and school life satisfaction. J KSSS 2013;51:435-448. 